\title{
Redevelopment support at Northparkes Mines
}

\author{
P. Brenchley Rio Tinto, Australia
}

L.A. Snyman Rio Tinto, Australia

J. Samosir Rio Tinto, Australia

B. Coxon Rio Tinto, Australia

\begin{abstract}
Northparkes is located $27 \mathrm{~km}$ north of the township of Parkes in central New South Wales, Australia. The operations consist of underground block cave mines and an ore processing plant which produces high grade copper and gold concentrate. Production is currently sourced from the E48 Lift 1 block cave mine and open cut stockpiles. Mining commenced at Northparkes in 1994 as an opencut operation. Underground block cave mining began in 1997. Northparkes was the first mine in Australia to use the highly efficient block cave mining method which relies on gravity and natural rock stresses to fragment and recover the ore.
\end{abstract}

The E48 extraction level is located approximately $581 \mathrm{~m}$ below surface and consists of 10 extraction drives and 214 drawpoints. Several stress measurements carried out at various levels in both E26 and E48 indicated a low underground regional stress environment and a low to moderate stress state in the E48 orebody. The E48 block used a post-undercut strategy that was initiated in 2009, with production commencing in September 2010 and cave-through to the surface occurring approximately four months later in January 2011.

An issue affecting production in 2011 was the stability of the E48 mine. A small portion of the drives on the extraction level began to deteriorate as the ground support system started to fail. The problem was temporarily fixed by stopping production in three extraction drives and tight filling selected areas within these drives (and drawpoints) with low strength concrete. This action provided immediate support and stability whilst allowing time to investigate potential ground support remedies. From these investigations it was decided to use resin injection technology and additional ground support to stabilise the rock in the aforementioned extraction drives as the concrete plug was excavated in a controlled advance and sequence. This made the area safe and ensured the ongoing safe operation of the E48 mine. The re-development of one of these drives began late in 2011, with the remainder to be redeveloped progressively in order to maintain the extraction level stability.

This paper looks at the strategies employed to safely re-open previously converged drawpoints and associated extraction drives that were subject to high abutment loading that was possibly associated with premature cave breakthrough.

\section{$1 \quad$ Introduction}

Northparkes Mines (Northparkes), located $27 \mathrm{~km}$ north of Parkes in central New South Wales, Australia, operates block cave and open cut mines and an ore processing plant, producing copper-gold concentrate that is sold to custom smelters in Japan and China. The mine has been operating since 1994 from two open cut mines E22 and E27 and three underground block caves E26 Lift 1 , E26 Lift 2 and E48, the latter being the only currently producing block cave. North Mining Limited (a wholly owned subsidiary of Rio Tinto) is the manager of the Northparkes unincorporated Joint Venture, which has the following ownership:

- Rio Tinto (80 \%)

- Sumitomo Metal Mining Oceania Pty. Ltd (13.3\%) 
- Sumitomo Corporation (6.7\%)

The E48 extraction level is located approximately $581 \mathrm{~m}$ below surface and consists of 10 extraction drives and 214 drawpoints as shown in Figure 1. Several stress measurements carried out at various levels in both E26 and E48 indicated a low underground regional stress environment and a low to moderate stress state in the E48 orebody before mining commenced.

\section{Background}

E48 was the first post-undercut block cave at Northparkes where significant stress loading conditions were experienced on the extraction level during undercutting in late 2010. This resulted in damage to some of the major pillars (Figure 1). Significant convergence (Figure 2) was experienced in the eastern region of the extraction level as active caving commenced in the west and abutment stresses increased along the undercut front which was being developed from west to east. The rapid cave breakthrough to surface occurred in early 2011, which is believed to be as a result of an intensive hydrofracturing programme undertaken in the E48 orebody. This early cave breakthrough, combined with the already weakened ground due to increased abutment stresses along the undercut front, resulted in elevated convergence and ground support damage as well as instability of drawpoints and their adjacent extraction drives 3,4 and 5.

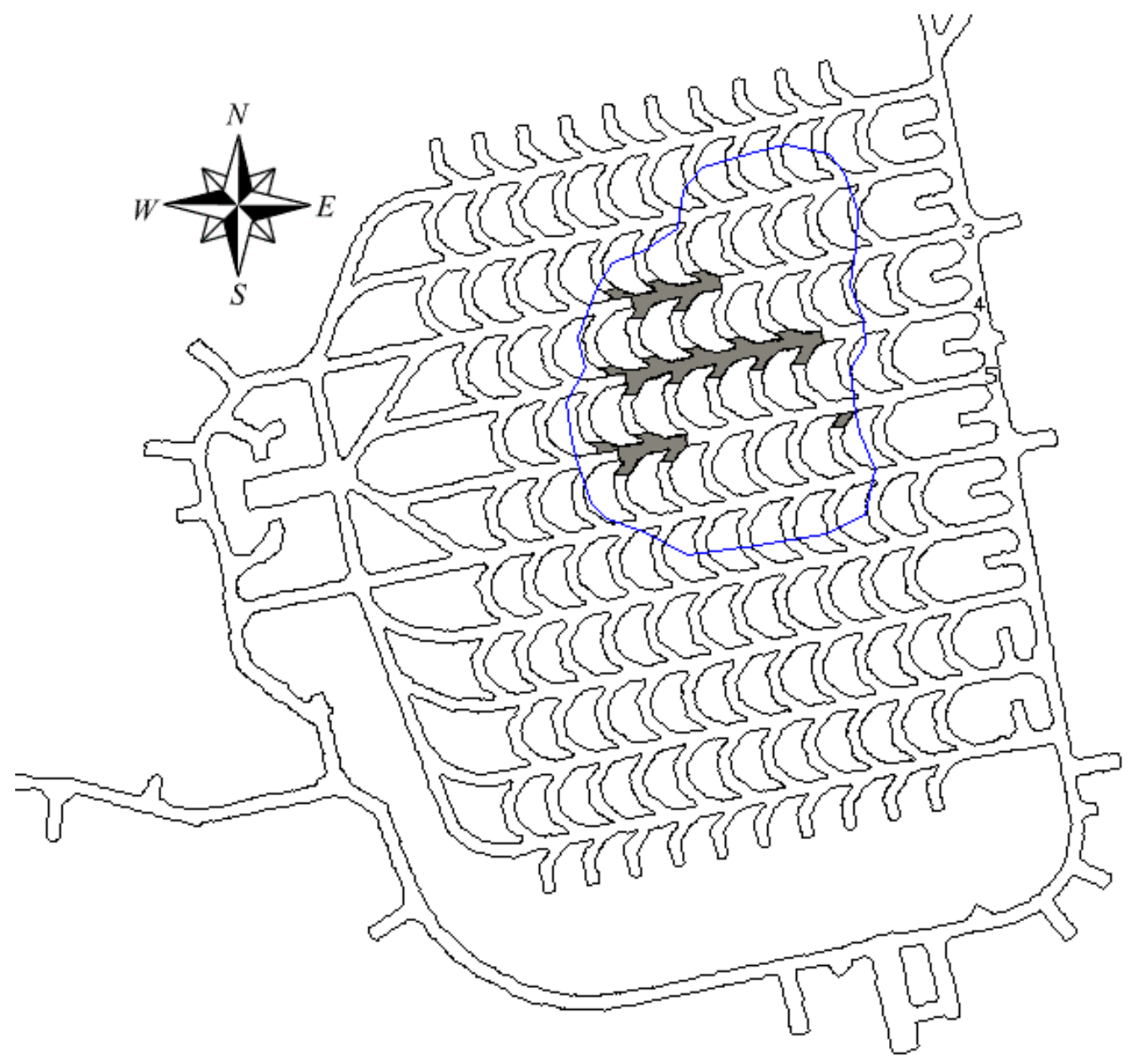

Figure 1 General layout of the E48 block cave showing concrete plugged drawpoints and outline of stress damage zone 


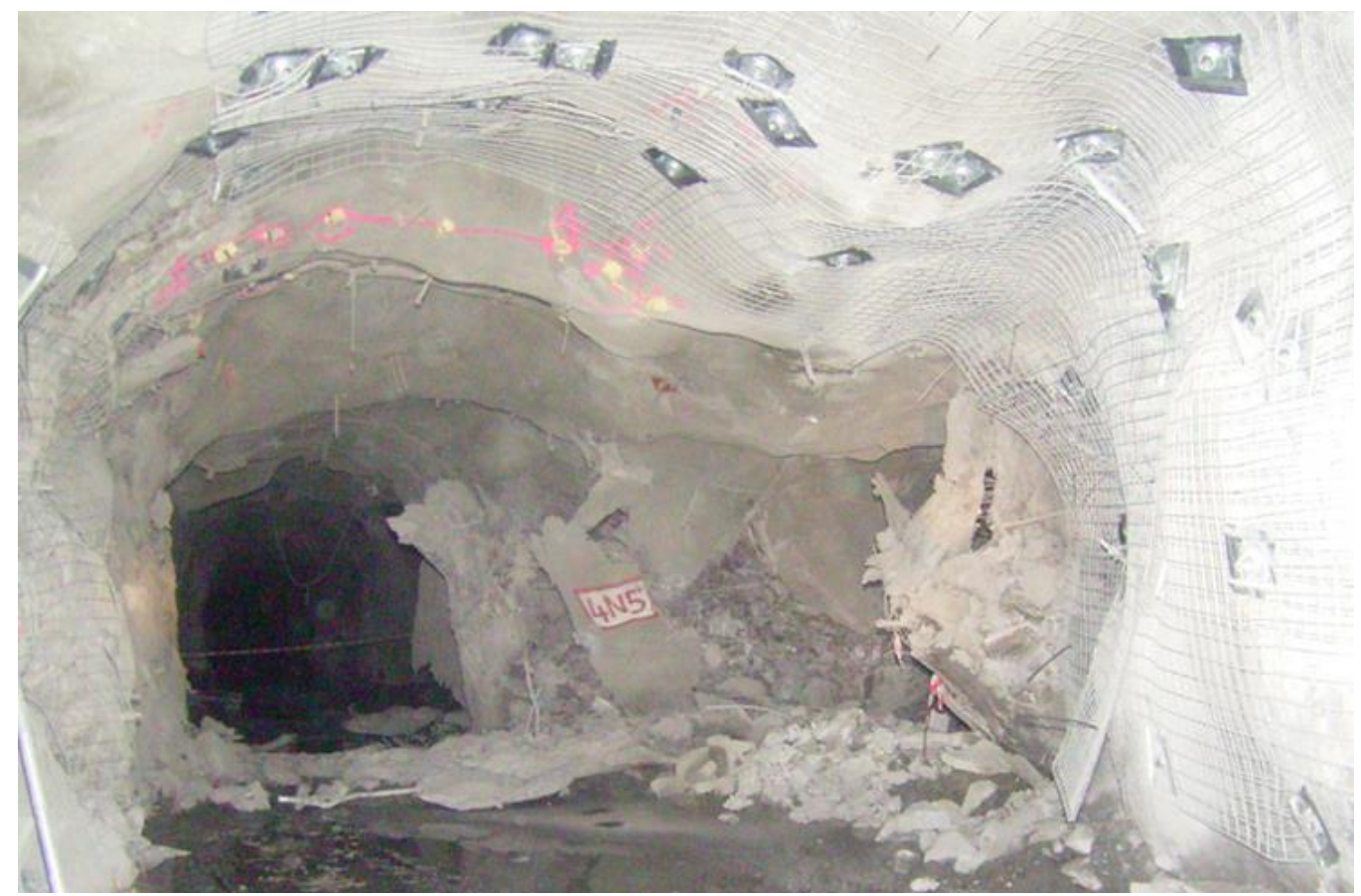

Figure $2{ }_{4} \mathrm{~N}_{5}$ bullnose and camelback damage, looking down ED4 from east to west, prior to concrete plugging

In order to provide immediate support and prevent widespread instability, the affected drawpoints and extraction drives were plugged with low strength concrete. Resin injection and cable bolt installation in the surrounding areas was undertaken during 2011 prior to redevelopment, to control convergence before it caused significant damage to pillars in other drives. Resin injection provided consolidation of the ground to enable anchor holes to be drilled and remain open. Twenty drawpoints and their adjacent extraction drives were ultimately plugged.

This was obviously disruptive to production with the possibility of losing ore reserves, poor ventilation flow, interruptions to the mine's loader automation project, as well as increasing operating risks, personal injury and equipment damage amongst other things. Several options were then assessed (by literature survey) to redevelop through the concrete sections of the extraction drives, including use of a roadheader, hydrocutting, an industrial rock saw and ultimately conventional drill and blast. The initial concept was to use traditional drill and blast excavation with massive steel sets, resin injection and cable bolts as the ground support regime to open the drives.

Following a visit to the Henderson Mine in Colorado, United States, it was decided that Northparkes would trial the use of resin injection and cable bolting only as this had been a successful strategy at Henderson, with increased drive recovery rates, improved risk management and reduced safety risks and costs (Peebles, 2012).

Based on industry precedence and the fact that extraction drive 3 was the least damaged of the three drives and was the shortest section to redevelop, it was selected as the stage 1 trial site. Of the 20 originally plugged drawpoints, 11 will not be recovered in the long term based on the ground conditions observed prior to filling these areas with concrete and the observations and experiences gained during the initial ED3 trial (stage 1).

The initial stage 1 trial involved the redevelopment of drawpoint 3N5 on the eastern end of the ED3 plug. A number of vital learnings were gained during this stage which was then applied to stage 2 redevelopment of ED5 and then ED3 from the west.

A relatively intensive instrumentation programme was implemented including tape extensometer convergence stations and a real-time monitoring network of multi-point borehole extensometers. 


\section{$3 \quad$ Learnings from stage 1 redevelopment}

Stage 1 redevelopment involved excavation of the concrete plug in ED3, approaching from east to west, and centred around a zone including drawpoint 3N5 and the adjacent extraction drive, as shown in Figure 2. The rock mass information available to base the ground support design on was limited, with mapping of the area restricted by the coverage of shotcrete in the drive. There were no probe holes available in the immediate $3 \mathrm{~N} 5$ vicinity nor was there extensometer information within this zone. Therefore the depth of damage was estimated based on probe holing and extensometer results from further west and east of the 3N5 zone, which indicated damage extents between 1.5-2.5 m deep. However, prior to plugging, shotcrete cracking in the backs in front of $3 \mathrm{~N} 5$ allowed for a fault structure to be mapped in the backs striking across the drive and angled into 3N5 drawpoint on a NNW/SSE angle. It was impossible to determine the extent and dip of the fault through mapping.

The extraction of the concrete plug was sequenced to open the extraction drive first, followed by the turn out for the 3N5 drawpoint. The installation of ground support was staged with the application of shotcrete and the installation of rockbolts on advance (one ring per metre) and cable bolts installed in a campaign every second cut (one ring at $2 \mathrm{~m}$ intervals). The length of the development cuts taken varied between 2.5-3 $\mathrm{m}$, therefore up to $6 \mathrm{~m}$ of concrete plug was excavated before cable bolt reinforcement was installed. In the drive around the location of the mapped fault (approximately $3 \mathrm{~m}$ length), additional $6 \mathrm{~m}$ long cable bolts were installed in the backs to reduce the cable bolt ring spacing to one ring per metre.

The drive in front of 3N5 was excavated with minimal convergence. However, poor ground was encountered when drilling around the fault zone in the backs and in the south sidewall across from the drawpoint. Once the turn out into the $3 \mathrm{~N} 5$ drawpoint was commenced and the intersection with the extraction drive opened up, the convergence in both the backs and the sidewalls accelerated. Drilling was increasingly difficult as the zone of broken ground was found to extend further into the pillars than had been predicted. The single boom jumbo used for drilling struggled to drill in the conditions encountered. It also struggled to provide timely installation of ground support, making progress very slow. Over time the convergence in the backs and sidewalls continued (Figure 3), despite the re-opening of the drawpoint and continuous draw, use of resin injection and further ground support installation. A combination of failed reinforcement elements and increasing convergence made the drive unserviceable, which in turn resulted in the closure of the area and subsequent re-plugging with concrete 8 months after opening.

CED3_14

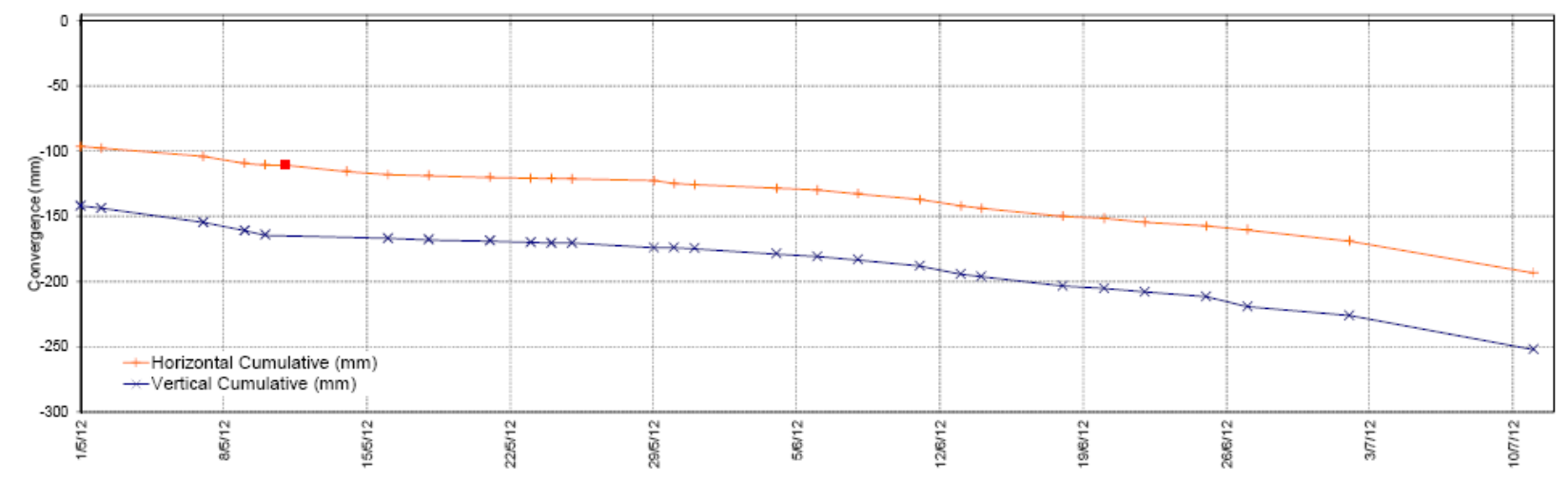

Figure 3 Convergence in ${ }_{3} N_{5}$ from May 2012 to July 2012

There were a number of factors that affected the success of the redevelopment in this area, the learnings from which were carried through to the design and redevelopment of stage 2, extraction drive 5.

The depth of damage predicted was 1.5-2.5 $\mathrm{m}$ from the surface. However, subsequent monitoring data in the $3 \mathrm{~N} 5$ area (MPBX extensometers) showed movement at depths of up to $6.7 \mathrm{~m}$ in the backs, and drilling condition records showed poor ground encountered in some areas ranging from approximately 0-2, 3-5.5 and 7-8 $\mathrm{m}$ in depth. It was concluded that based on these observations, the $6 \mathrm{~m}$ long cable bolts installed, 
with $2 \mathrm{~m}$ debonded sections at the collar were not achieving adequate anchorage into competent ground. $9 \mathrm{~m}$ long cable bolts were then installed with $5 \mathrm{~m}$ debonded sections to allow for the greater depth of damage. However, by the time they were installed, the rock mass had further deteriorated with the ongoing convergence and their installation quality in broken ground was questionable. They failed to arrest the convergence in the backs and sidewalls. The learning was that depth of damage is impossible to be accurately estimated in the redevelopment area using probe hole information in surrounding areas. The depth of damage could vary significantly over a small distance, therefore future redevelopment should include preparatory drilling above the redevelopment zone for more accurate estimation. It was found that the depth of damage was not only shallow, but there were a number of intervals of damage separated by competent ground. Therefore future cable bolt designs would need to compensate for this with varying debonded lengths. An additional learning was that resin injection would be required prior to taking each cut and in-cycle with the first and second pass support regime, to target several horizons, not only the shallow rock mass.

The equipment and labour used to undertake the redevelopment work in stage 1 was in hindsight not ideal. The single boom jumbo used was inadequate to drill in the deteriorated conditions encountered, and therefore some cuts could take up to one week for first pass reinforcement to be installed. Each cut required a significant amount of resin injection to make drilling possible which further slowed down the progress. Given the delays to installation it was obvious through visual inspection that the ground was able to relax, with shotcrete cracking evident, making the arch profile difficult to generate, contributing to the further relaxation of the backs. The redevelopment work was undertaken using existing experienced operators, not an additional redevelopment crew. This meant there was limited labour available to respond to changing conditions and additional support requirements. The key learning was focussed on the importance of timely installation of ground support. Redevelopment work should not be undertaken without the appropriate fit for purpose equipment and adequate resources to complete each cut within a reasonable timeframe, thereby limiting relaxation of the rock mass. In conjunction with this, the cable bolts should be installed with each cut to limit the extent of relaxation in the rock mass prior to installation which makes drilling and grouting very difficult.

The extraction sequence coupled with the slow advance rate meant that the drive and the 3N5 intersection were opened three weeks prior to draw commencing from the 3N5 drawpoint. The convergence in the backs accelerated after opening the intersection to full span and it was observed that the loading above the major apex was pushing the backs down, creating crunching of the shoulders and bulging of the sidewall pillars (Figure 4). The first generation of cable bolts in the drive began to show loading on their plates and over a three week timespan, the shotcrete in the backs cracked up as they moved down around the cable plates. Without initiating cave draw there was no way of reducing loading. By the time the reinforcement of the area was complete and draw commenced, the rock mass had deteriorated so badly that any load removal through draw had little effect to slow down the convergence. It was therefore concluded that future redevelopment of drawpoints should use a reverse excavation sequence; redeveloping the turn-out to the drawpoint first, enabling draw to commence, before removing the plugged drive and opening up the intersection. This way the largest span would only be created after a consistent level of draw has been established to remove compacted material above the major apex, creating porosity in the caved material and therefore reducing loading. 


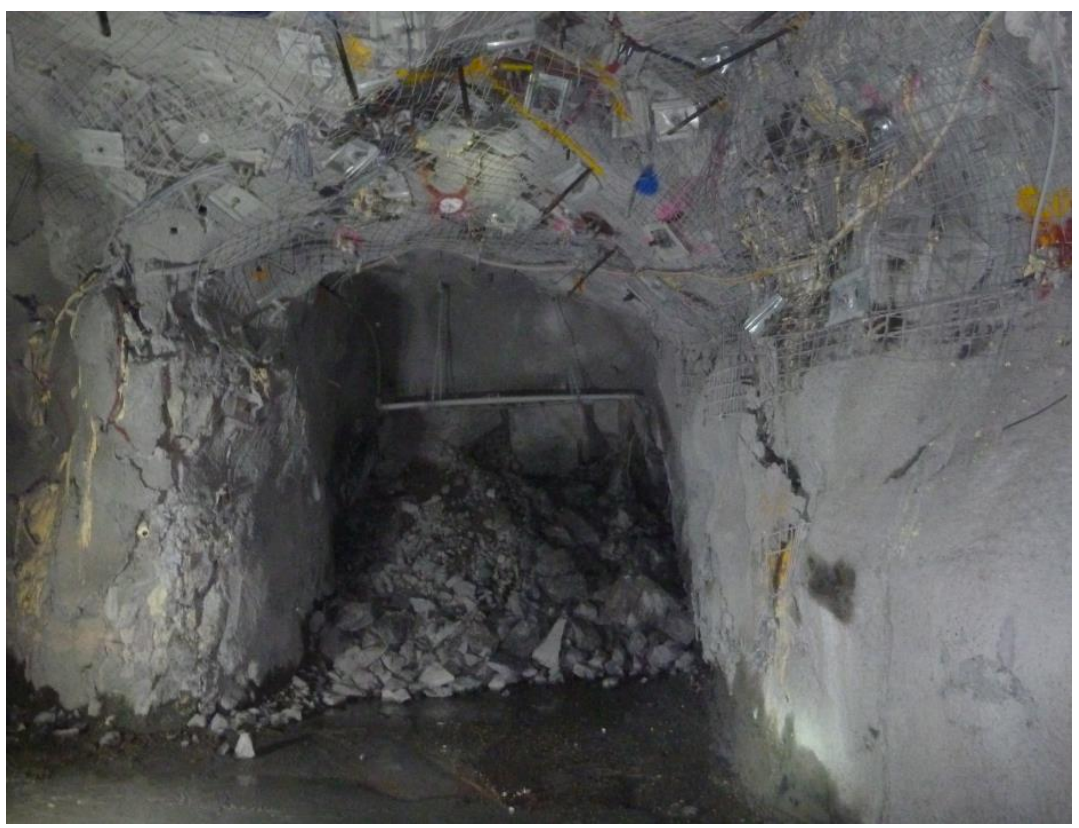

Figure 4 Cracking of the ${ }_{3} \mathrm{~N}_{5}$ drawpoint shotcrete indicating loading

\section{$4 \quad$ Stage 2 - redevelopment of ED5}

Redevelopment in ED5 was commenced in April 2012 from the eastern side. A dedicated redevelopment crew was formed, equipped with a twin boom jumbo with shortened rails to effectively bolt in a $4.5 \mathrm{~m}$ heading. It is known that one of the key parameters of successful reopening is maintaining a continuous sequence. A $3 \mathrm{~m}$ advance was taken in every blast through the drive and into $5 \mathrm{~S} 6$ drawpoint to prevent a wide span area that would most likely lead to an increasing level of instability.

A combination of various ground support elements was used to provide improved coverage and performance. Resin injection is done prior to blasting which is able to penetrate into the defects/voids, filling and re-consolidating broken ground. During the initial resin injection activities the injection drill holes are angled 25 and $45^{\circ}$ relative to the concreted face (Figure 5). The face is then ready for blasting. After blasting, primary ground support is applied including $50 \mathrm{~mm}$ fibrecrete, $5.6 \mathrm{~mm}$ mesh from $0.5 \mathrm{~m}$ from the floor with minimum overlap of $200 \mathrm{~mm}, 2.4 \mathrm{~m}$ long rockbolts and further shallow resin injection (Figure 6). This primary ground support needs to be installed as soon as possible after blasting due to the assumption of broken rock mass conditions that will result in a reduced stand up time. Finally, $6 \mathrm{~m}$ long $21.8 \mathrm{~mm}$ diameter super strand cable bolts ( $590 \mathrm{kN}$ capacity, with a $3 \mathrm{~m}$ long debonded section) are installed in the walls and $9 \mathrm{~m}$ long $21.8 \mathrm{~mm}$ diameter ( $5 \mathrm{~m}$ long debonded section) super strand cable bolts are installed in the shoulder and back of the opening (Figure 7).
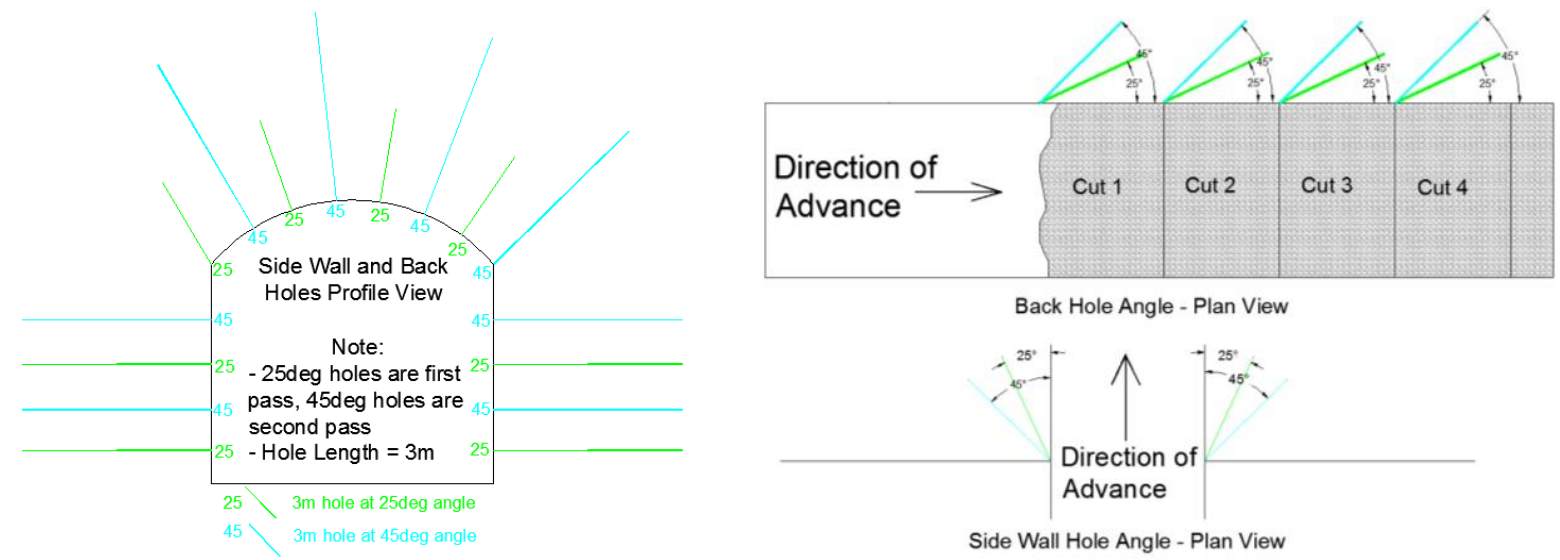

Figure 5 Advanced resin injection 

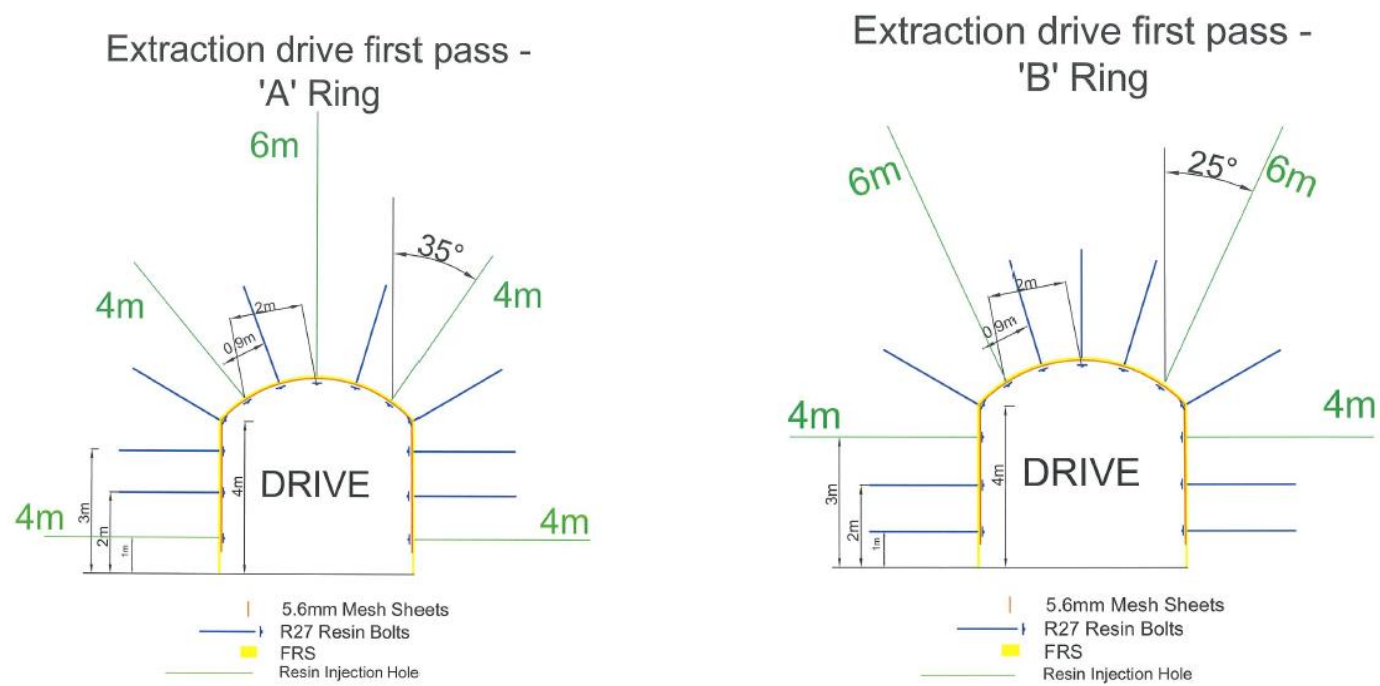

Figure 6 Extraction drive primary ground support and resin injection plan

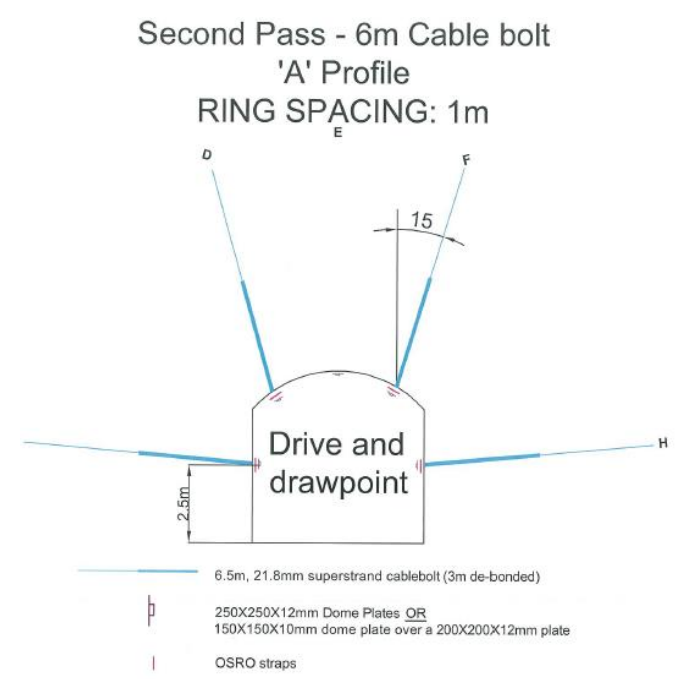

Second Pass

Drive and drawpoint

RING SPACING: $1 \mathrm{~m}$

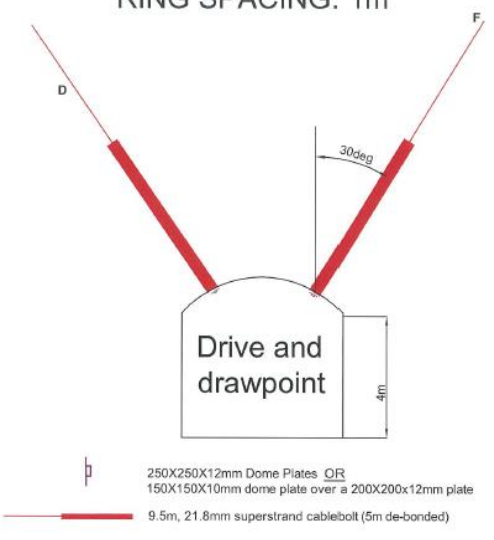

Second Pass - 6m Cable bolt 'B' Profile

RING SPACING: $1 \mathrm{~m}$

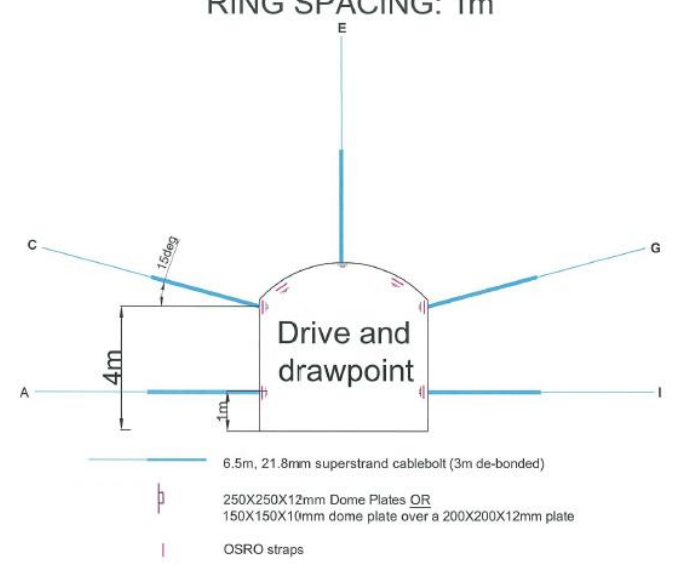

Second Pass

Drive and drawpoint RING SPACING: $1 \mathrm{~m}$

Figure 76 and $9 \mathrm{~m}$ cable bolt plans

From the drilling condition records, it was confirmed that the ground is fairly broken behind the brow of the draw point. The $6 \mathrm{~m}$ long cable bolts were installed to within $1.5 \mathrm{~m}$ from the drawpoint steel set, while all $2.4 \mathrm{~m}$ long rockbolts were installed to the drawpoint steel set. 
Once the $5 \mathrm{~S} 6$ drawpoint was opened, the bogging strategy became priority. The tonnage called for was slowly increased (5 buckets/day, 10 buckets/day, 15 buckets/day, 20/24 buckets/day) to give the caved material time to 'fluff up'. From previous experience in E48, this has proven to be the best sequence for the initial draw point opening.

After $5 \mathrm{~S} 6$ was opened, the redevelopment activity focussed on the western side of ED5, to allow bogging to continue from the newly opened drawpoint on the eastern side and redevelopment advance to continue from the west. In June 2012, ED5 was completely broken through. It took two weeks to complete the ground support installation, including cable strapping of the bull nose. With ED5 open, the activities to open 5N8 were a lot more efficient due to better ventilation flow and safe access.

The same philosophy as described above was applied to the reopening of $5 \mathrm{~N} 8$, with the same ground support system and bogging strategy applied. Based on the ground conditions observed prior to filling, these areas with concrete, as well as the experiences gained during the stage 1 trial and stage 2 execution, it is likely that a number of draw points will not be recovered in the long term, due to the inability to effectively re-support these areas. In such areas where the rock mass and pillars have experienced extreme deterioration, leaving draw points filled with concrete provide additional support to the weakened rock mass and are likely to provide sufficient assistance to allow the main extraction drive to be re-established. From start-up of re-development until production commenced in 5S6 (Figure 8) and 5N8 (Figure 9), convergence was maintained between 0.01 and $0.3 \mathrm{~mm} /$ day, except during blasting when there was an increase in convergence immediately after blasting. This was proven by visual observations that indicated no significant increasing level of damage to ground and ground support.

\section{Total Cumulative Convergence on 556}

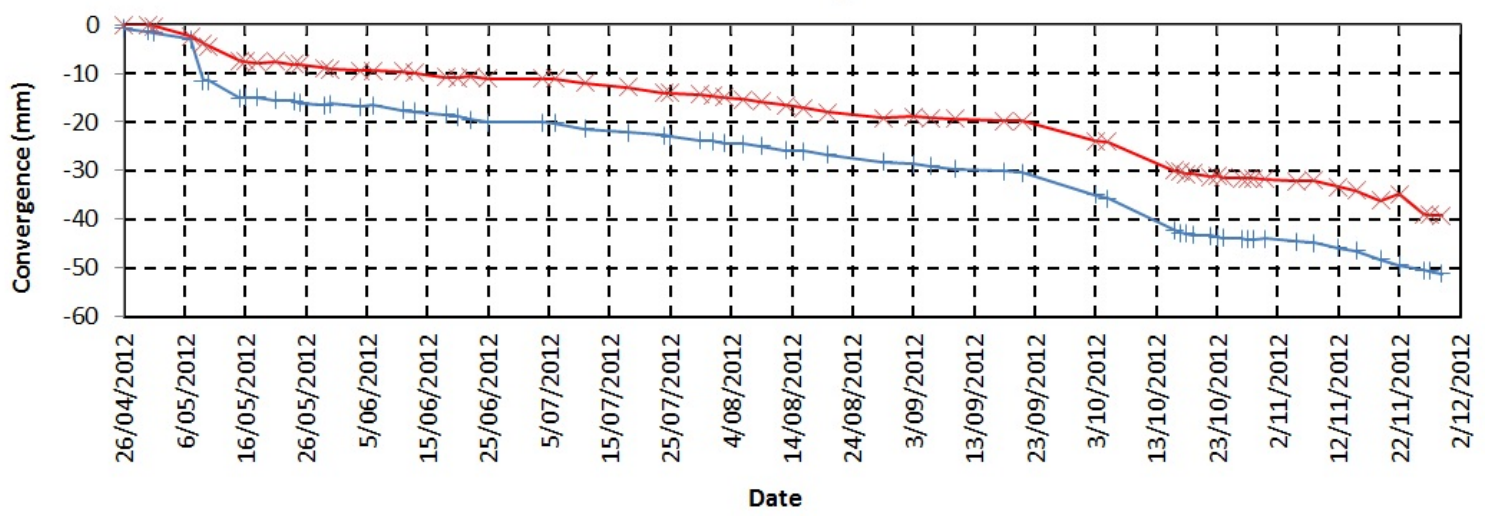

— Horizontal Cumulative Displacement

$\leftarrow$ Vertical Cumulative Displacement

Figure 8 Cumulative convergence in 556

Total Cumulative Convergence on $5 \mathrm{N8}$

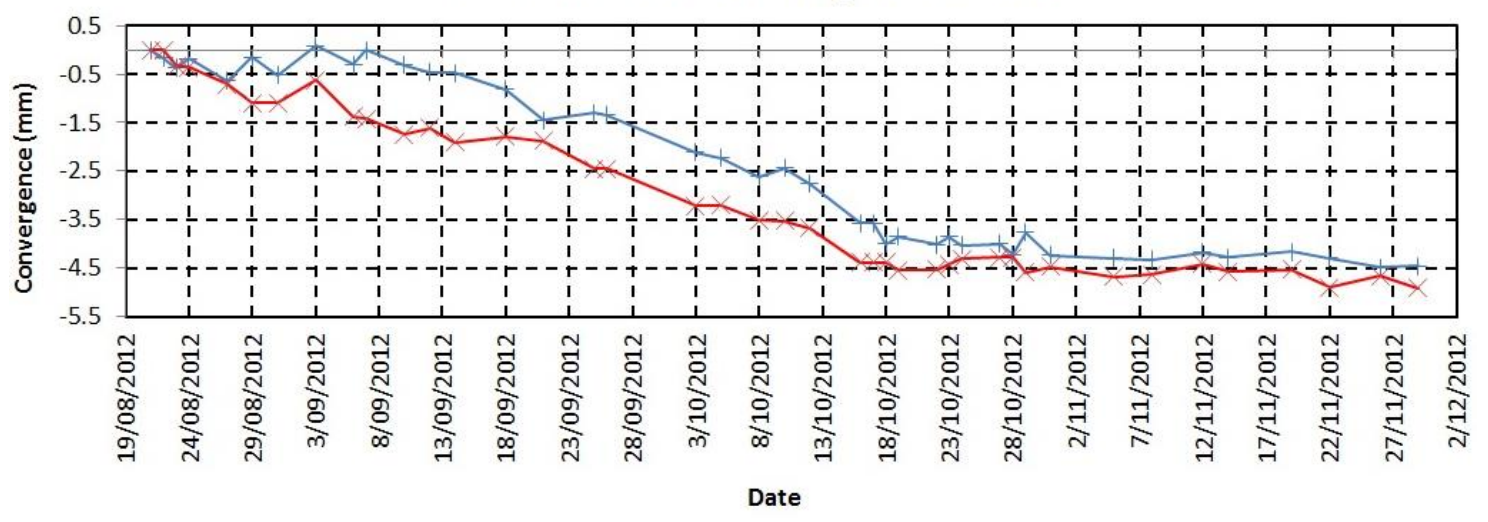

—Horizontal Cumulative Displacement $\quad \leftarrow$ Vertical Cumulative Displacement

Figure 9 Cumulative convergence in ${ }_{5} \mathrm{~N} 8$ 
From experience during the ED5 redevelopment, it is confirmed that a combination of ground support design and sequencing, resin injection and cable bolt installation, along with an improved overall excavation schedule until draw is restarted to relieve stress loading, will combine to reduce convergence levels and thus reduce the likelihood of primary rockbolt failure and further damage.

\section{Assessment of project}

The primary objective of the redevelopment of the stress induced damaged areas was to access and ensure recovery of the ore reserves, once an acceptable method of redevelopment had been sourced. Secondary objectives would have been to gain improvements in operational aspects such as ventilation, equipment interaction and an overall safety improvement. The filling of the drawpoints and associated extraction drive areas with concrete obviously impacted on the overall efficiency of the cave mine operations. Utilising experience gained during the early stages (as discussed in stage 1 redevelopment), allowed for the redevelopment and sequencing of the support cycle to be improved, which has resulted in the successful reopening of extraction drives ED3 and ED5, and at the time of publication one of the draw points in ED4 had also been reopened, which is in accordance with the overall project schedule.

From the previous discussions, it is obvious that careful and methodical adherence to the given resin injection and ground support strategy had to be maintained. The planned redevelopment at first pass was labelled as a higher risk situation when compared to standard development in virgin ground conditions, and it was acknowledged that during the stage 1 trial, Northparkes Mines development personnel did not have the equipment and expertise to undertake the resin injection which was part of the cycle. This aspect was outsourced in the early stages of the redevelopment, with Northparkes Mines personnel covering the drill, blast, bogging and ground support activities, until sufficient experience was gained for the mine development team to take on the resin injection aspects as well. It is a credit to the redevelopment teams' strict adherence to the strategy and attention to detail that the reopening of the extraction drives ED3 and ED5 with re-establishment of the drawpoints was completed safely.

Once the resin injection and ground support strategy was designed, initial cost estimates were drawn up for management approval. These initial cost estimates indicated that the redevelopment costs would be much greater when compared to budgeted capital development rates (in virgin ground), whilst the final costs to date indicate that the redevelopment costs of reopening up ED3 and ED5 are approximately 10 to 12 times greater than budgeted capital development. The major unknown cost element was the consumption/volume of resin injected into the rock mass. Attempts were made to forecast the anticipated resin consumption based on the extent of the ground damage observed prior to the plugging of drawpoints and extraction drives. However, these forecasts could not take into account any time dependent damage that could have occurred prior to redevelopment and reopening. Any poor or severe ground conditions encountered during the redevelopment process required additional resin injection to stabilise the ground. The resin injection process was continually repeated until sufficient back pressure was generated, or the drillability of the ground conditions improved, allowing for the primary rockbolts in tandem with the 6 and $9 \mathrm{~m}$ cable bolts to be installed. In all cases the redevelopment would only advance once the 6 and $9 \mathrm{~m}$ cable bolts had been successfully installed, as per ground support cycles illustrated in Figures 6 and 7 .

During the redevelopment of the drives and reopening of the draw points, the immediate and surrounding areas were frequently inspected by the geotechnical engineers, and, if required, additional ground support and or resin injection was recommended. Photographic records were also taken by the geotechnical engineers, using standard digital cameras as well as the Adamtech camera, allowing for a three-dimensional spatial representation to be created from the photographs. These regular inspections and photographs were used to assist with on the job training for the crews and also on advising the development crews when shift rosters came about which meant that new crews would be on site. Increased vigilance from supervisors and management, combined with regular geotechnical inspections kept a high level of awareness amongst the crews working in the redevelopment areas, which most certainly contributed to the safety of the project, as well as the quality of work done and the overall quality of redevelopment achieved. 
Taking into account the overall impact that the plugged areas have had on the operational aspects of the E48 block cave, the safe and successful reopening of five drawpoints within ED3 and ED5 has created improved flexibility with production bogging, as both ED3 and ED5 now allow full and complete access for the entire length of the drives, as well as improved ventilation and drainage conditions throughout the level.

\section{Conclusions}

Upon review of the options available, Northparkes elected to proceed with the plugging and filling of the drawpoints as well as selected portions of the affected extraction drives. Once stability of the affected areas had been achieved, a collaborative effort was directed towards a ground support solution and methodology to allow for safe reopening of the affected areas. Once the use of resin injection in combination with primary and secondary ground support strategy had been designed and accepted, detailed planning combined with safe and steady advancement in the redevelopment areas has successfully allowed for extraction drawpoints to be safely reopened securing access to related reserves.

The successful implementation of resin injection and purposely designed ground support illustrates that searching for potential solutions outside of current operational experience in tandem with management participation and following a risk assessment process can have successful outcomes.

The following main conclusions can be made from this body of work:

1. Timely tight backfilling with low strength cement of three extraction drives and 20 drawpoints provided time for the technical teams to design, cost and gain management approval for a staged redevelopment strategy.

2. The management team recognised that the redevelopment strategy and its associated project and cost schedule would change once the stage 1 trial works were completed.

3. Having the correct equipment, training, safe work procedures and dedicated crews are required in complex rehabilitation operations. This can, and often does, involve the use of outside contractors.

4. Resin injection (to refusal) is an effective method for reconsolidating broken ground; allowing the use of conventional ground reinforcement systems to control convergence.

5. Of the 20 abandoned drawpoints, five have been redeveloped and are in operation and nine will be redeveloped in 2013.

\section{Acknowledgement}

This paper has been compiled from published and unpublished Northparkes and Rio Tinto reports. The contribution of all members of the Technical Services team alongside with personal communication with the redevelopment team members is gratefully acknowledged. Special thanks are extended to both Northparkes Management and Rio Tinto Management for their permission to compile and publish this paper.

\section{References}

Peebles, E. (2012) E48 Re-Development Project - Project Execution Plan, Rio Tinto internal document. 